\title{
Endovascular management of a complex high-flow lower limb arteriovenous malformation: Case report and literature review
}

\author{
Manejo endovascular de una malformación arteriovenosa compleja de alto flujo en \\ miembro pélvico: Reporte de caso y revisión de literatura \\ María C. Ornelas-Flores', Guillermo A. Rojas-Reyna², Carlos G. Hinojosa-Gutiérrez ${ }^{3}$, and \\ Stefany González-de Leo ${ }^{2 *}$ \\ ${ }^{1}$ General Surgery Service; ${ }^{2}$ Vascular Surgery Service; ${ }^{3}$ Radiology Service. ABC Medical Center, Mexico City, Mexico
}

\begin{abstract}
Introduction: Lower limb high-flow arteriovenous malformations (AVM) are a rare pathology with a chronic and progressive evolution. Development in imaging and treatment has helped to improve outcome. Objective: We report a case treated with multi-session endovascular embolization therapy with favorable results. Case report: $A$ 44-year-old man referred with a complex high-flow lower limb AVM, previously treated with covered stents and a bypass. Six endovascular interventions were performed, combining different embolization methods. Conclusion: Endovascular treatment is a safe and effective option for high-flow AVMs. Embolization should be done carefully to prevent complications that could threaten the patient's limb or life.
\end{abstract}

Key words: Arteriovenous malformation. Endovascular surgery. Embolization. Lower extremity.

\section{Resumen}

Introducción: Las malformaciones arteriovenosas (MAV) son una patología con un curso crónico y una evolución progresiva. Objetivo: Reportar el caso de una MAV tratada con embolización endovascular en múltiples sesiones con resultados favorables. Reporte de caso: Masculino de 44 años referido con una MAV de alto flujo del miembro pélvico derecho, tratado previamente con un stent recubierto y un bypass. Se realizaron seis sesiones endovasculares combinando diferentes métodos de embolización. Conclusión: El manejo endovascular de las MAV de alto flujo es seguro y efectivo, debe de realizarse cuidadosamente evitando poner en riesgo la extremidad del paciente e incluso la vida.

Palabras clave: Malformación arteriovenosa. Cirugía endovascular. Embolización. Extremidad inferior.

\section{Introduction}

Arteriovenous malformations (AVM) are congenital and they are related to an autosomal dominant inheritance pattern. Approximately $90 \%$ of AVMs are diagnosed at birth'. They include a wide spectrum of lesions that can present initially as an incidental finding $^{2}$. An AVM can combine multiple vascular lesions such as fistulas, aneurysms, ectasia, and stenotic vessels $^{3}$. AVMs appear when there is a deficient

\section{Correspondence:}

*Stefany González-de Leo

Sur 136, \#116, Torre Mackenzie

Las Américas, Álvaro Obregón

Date of reception: 21-07-2020

C.P.: 01120, Ciudad de México, México

E-mail: fanyglez@ hotmail.com

0009-7411/@ 2020 Academia Mexicana de Cirugía. Published by Permanyer. This is an open access article under the terms of the CC BY-NC-ND license (http://creativecommons.org/licenses/by-nc-nd/4.0/). 
regulation in between the signaling, proliferation, differentiation, maturation, adhesion and apoptosis of vascular endothelial cells, smooth muscle, or pericytes ${ }^{4}$.

AVMs represent a rare condition, and they are the least common type of congenital vascular malformations. They can be classified in low-flow, high-flow, and mixed AVMs. High-flow AVMs represent $10 \%$ of lower-limb AVMs and the genetic is unknown, it is believed to involve notch signaling pathway alterations ${ }^{1}$. Typically, they have a progressive chronic evolution, presenting themselves with an epicenter or nidus. The most common place to find them is the cranium, followed by the extremities and finally in the trunk. Some known triggers are puberty, trauma, thrombosis, infections, and pregnancy ${ }^{1}$. They have a wide range of clinical manifestations, from peripheral swelling to cardiac failure. Some common manifestations in the clinic are pulsatile lesion, palpable thrill, edema, pain, hypertrophy, distal ischemia, and skin lesions or atrophy ${ }^{4}$.

Developments in classification, imaging, and management have helped to improve the outcome. In 1996, Schoëbinger classified AVMs from Stage I to IV according to the clinical symptoms presented. At present, Hamburg morphological classification and International Society for the Study of Vascular Anomalies classification are helpful for their categorization. ${ }^{5}$. Different imaging modalities are used to evaluate the nature, extent, and complexity of the malformation to help plan appropriate treatment ${ }^{2}$. Ultrasonography is the preferred initial study; some findings are venous arterialization, arteriovenous shunts, pulsatile, or high flow. Contrast computed tomography (CT)-scan allows evaluation of AVMs and their complications such as acute hemorrhage and confirms the existence of calcifications, thrombus, or concomitant lesions ${ }^{6,7}$. Magnetic resonance imaging has become the most valuable modality for basic anatomic evaluation that demonstrated the extent of AVM. Angiography is an important part of anatomical assessment, especially in complex high-flow AVMs. It is used as a part of pre-operative assessment and during interventional procedure $^{2}$. Arteriographic classification of AVMs was proposed to classify them based on the arteriographic findings of the nidus being helpful in predicting the outcome of treatment ${ }^{8}$.

Management should consider the progressive nature and the high risk of recurrence ${ }^{9}$. Treatment should also be customized depending on size, type, and anatomical location. Treatment can be either conservative or invasive; including endovascular and surgical resection. Some treatment indication criteria for AVMs are hemorrhage, heart failure, arterial ischemic complications, chronic venous hypertension, disabling pain, functional impairment, severe cosmetical deformity, and lesions located at life-threatening vital areas ${ }^{10}$. Embolization and sclerotherapy are preferred for definitive treatment of surgically unreachable lesions and for initial therapy of accessible ones ${ }^{11,12}$. A multidisciplinary approach is the goal for a better understanding of these complex clinical entities and also for a successful outcome ${ }^{13}$.

High-flow AVMs are a challenge due to its frequency of recurrence and even worsening if the correct approach is not selected. We report a case of a patient with a complex high-flow lower limb AVM, previously treated with covered stents and a femoral to popliteal bypass who came to our institution with persistent pain and swelling and was successfully treated with multi-session endovascular therapy.

\section{Case report}

The subject in this article signed an informed consent form that has been approved by the institution; no further Institutional Review Board approval was needed.

We report a case of a 44-year-old man with a 10year history of swelling and pain on the right leg. The only relevant finding in his medical history was an accident which consisted of a 2-story fall when he was 5 years old. The rest of his medical history was uneventful, with no family history of vascular malformations. He was previously treated at another institution with covered stents at the superficial femoral and profunda femoral arteries. The superficial femoral stent occluded, and he presented with acute limb ischemia for which a femoral to popliteal bypass was done at the time.

He came to our institution complaining of persistent and worsening swelling, progressive pain and a nonhealing ulcer on the right leg. A congenital etiology with a traumatic trigger after the childhood fall was suspected, but a pure traumatic etiology cannot be ruled out. On examination, the patient presented limb asymmetry, the right leg with a diameter measured of $48 \mathrm{~cm}$ in comparison to the left leg with a diameter of $38 \mathrm{~cm}$. $\mathrm{He}$ also presented with multiple varicose veins, edema, ochre dermatitis and atrophic changes in the skin, absent distal pulses and an ulcer in the medial malleolus of $7 \times 8 \mathrm{~cm}$ with irregular and necrotic borders. 
Diagnostic approach was initially performed with a transthoracic echocardiogram with a left ventricle ejection fraction of $75 \%$, dilated right ventricle and biauricular dilation. Doppler ultrasound (US), with a vascular malformation, formed by arterial and venous turbulent flow. The angio-CT (CTA) showed dilation of the aorta and a right iliac vein aneurysm with a maximum diameter of $7.6 \mathrm{~cm}$, multiple tortuous vessels through the leg, femoral superficial artery with surgical changes due to the bypass and a stent in the superficial femoral and profunda femoral arteries (Fig. 1). Six endovascular interventions were performed within 4 months, combining different embolization methods for afferent vessels occlusion. All the sessions took place in the angio-suite under general anesthesia.

The CTA findings were then confirmed in the first endovascular session with the angiography, which also detailed multiple feeding vessels from the profunda femoris and superficial femoral artery. AVM was classified as a type IIIb according to the angiographic classification ${ }^{4}$, with multiple shunts between arterioles and venules and dilation of the fistulae. In the first endovascular intervention, feeding arteries embolization was made through a cross-over arterial left femoral access with selective catheter placement in the feeding vessels and then five Onyx-34 embolizations were made, final arteriography showed presence of multiple arteriovenous fistulae (Fig. 2A). In the second session, the left femoral puncture was done and a cross-over was made again with selective embolization with Onyx-34 of the hypogastric feeding vessels and selective embolization of right common femoral feeding vessels was done and five coils were used (Fig. 2B). In the third session, a direct puncture in the right femoral artery, then a selective feeding arteries embolization with Onyx-34 and eleven coils to the common and superficial femoral feeding vessels was done (Fig. 3A), together with direct US-guided puncture of the venous dilated veins. In the fourth and fifth sessions, an embolization with Onyx-34 and six coils both to superficial femoral feeding vessels and dilated superficial veins was done (Figs. $3 \mathrm{~B}$ and $\mathrm{C}$ ).

Open surgery was attempted for resection of accessible arteriovenous fistulae at the femoral bifurcation, fistulas between the femoral artery and vein were ligated and a selective arteriography was made clamping the superficial femoral and the profunda in different times, finding that all the remaining fistulous vessels were coming from the profunda femoris (Fig. 4). A final session was planned with selective catheter placement in the profunda femoris and embolization of
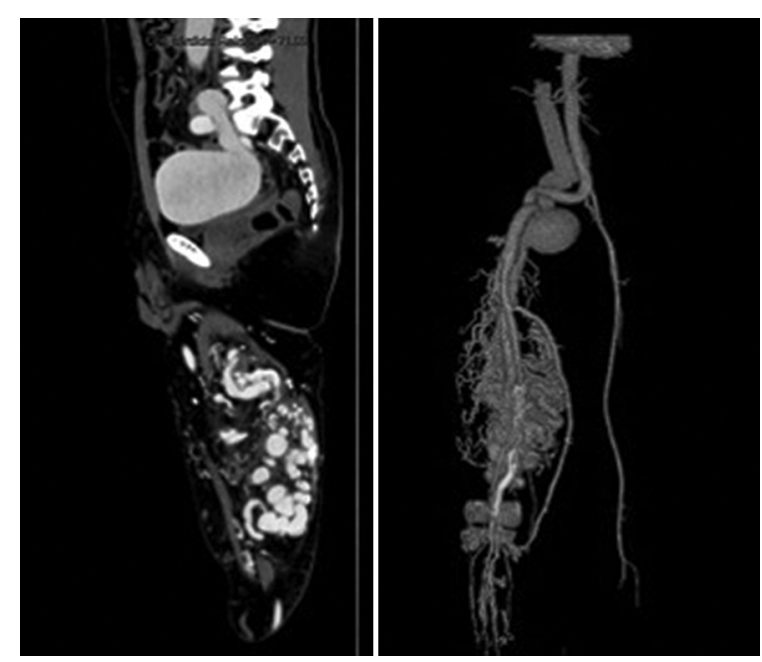

Figure 1. Angio-computed tomography sagittal and 3D-reconstruction showed an aneurysm in the right iliac artery and an arteriovenous malformation on the leg with 18 multiple tortuous vessels, femoral superficial artery with surgical changes due to the bypass and a stent in the superficial femoral and profunda femoral arteries.

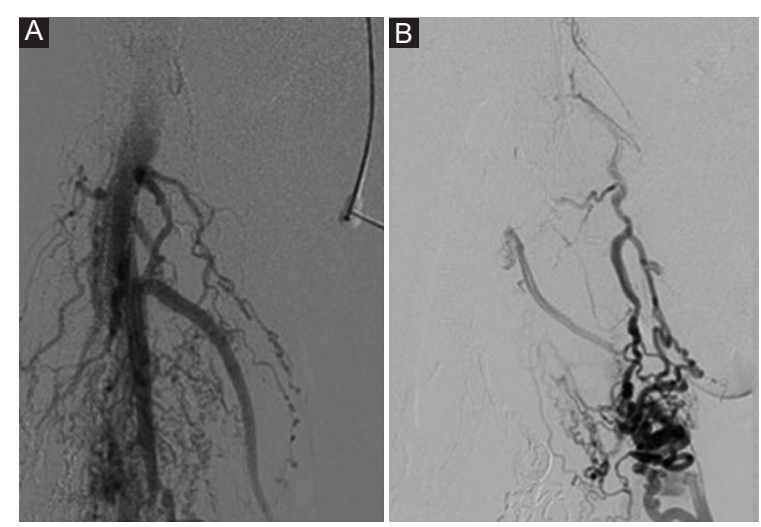

Figure 2. Final angiography after first embolization session with Onyx 34. A: multiple feeding vessels from the profunda femoris and superficial femoral artery. B: control angiography after second session with selective afferences embolization with Onyx-34 and five coils.

feeding arteries with Onyx-34 and 2 coils, the last arteriography showed significant decrease in fistulous shunts (Fig. 3D). There were no complications documented in any of the sessions, and the patient was discharged in 24-48 h every time.

Figure 5 shows the evolution of the medial malleolus ulcer after the endovascular treatment and figure 6 shows the CTA 3D-vascular reconstructions evolution after treatment. Nowadays, the patient has minimal symptoms, with significant improvement in pain, with improved function and similar thigh diameter and the ulcer is significantly diminished in diameter as shown below. 

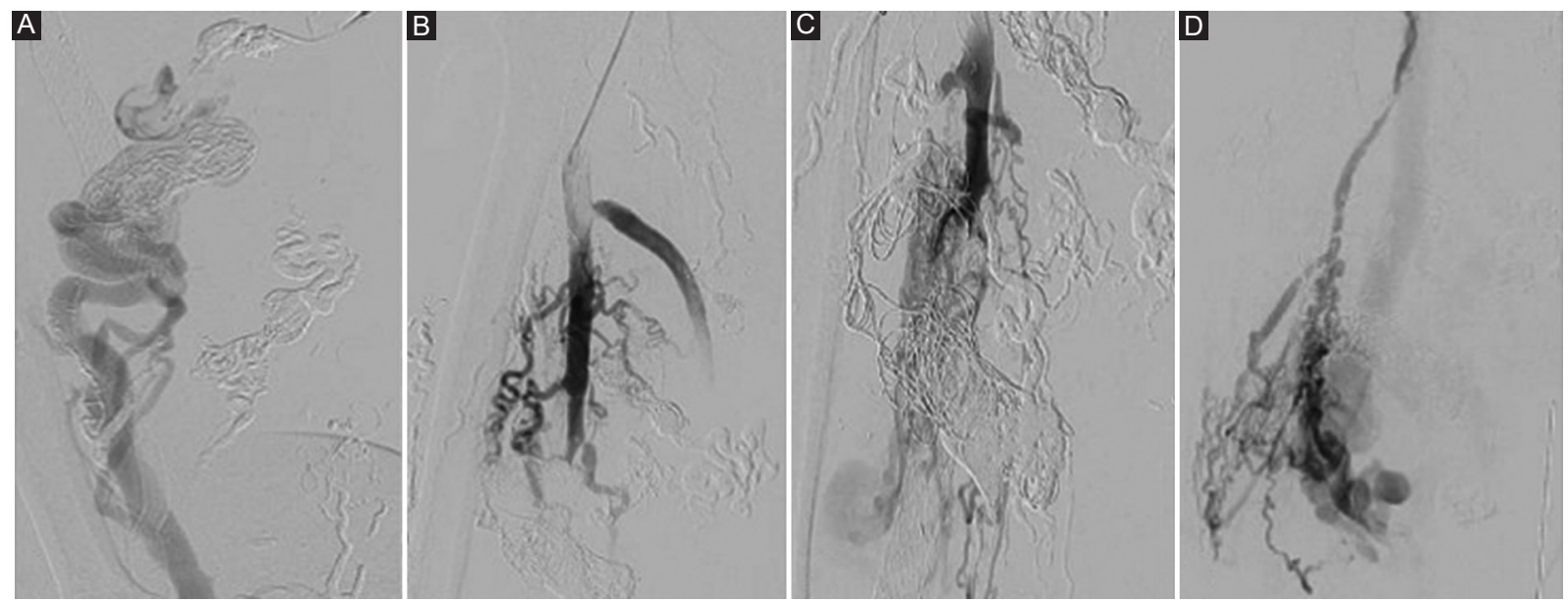

Figure 3. Third to sixth endovascular sessions. A: in the third session, a direct puncture in the right femoral artery, then a selective afferences embolization with Onyx-34 and eleven coils. B-C: in the fourth and fifth sessions, an embolization with Onyx-34 and six coils. D: after open surgery attempt, a final session was planned with selective catheter placement in the profunda femoris and embolization of afferences with Onyx-34 and 2 coils, the last arteriography showed significant decrease in fistulous shunts.

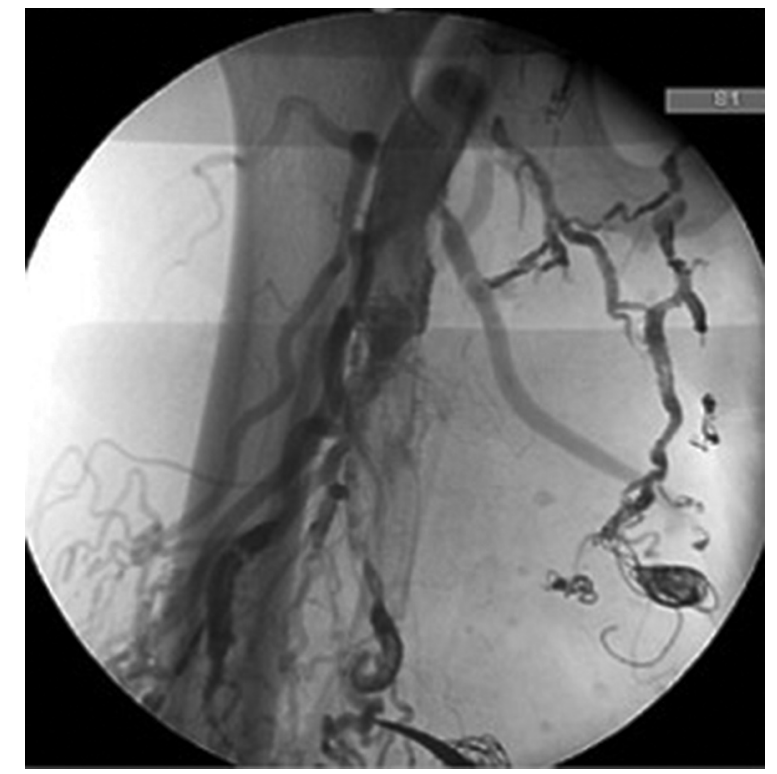

Figure 4. Fistulas between the femoral artery and vein were ligated and a selective arteriography was made clamping the superficial femoral and the profunda in different times, finding that all the remaining fistulous vessels were coming from the profunda femoris.

\section{Discussion}

In the physiopathology of AVMs, initially there are anomalous shunts between arterial and venous systems without stabilizing the function of the capillaries in between them ${ }^{8}$. The arterial flow is diverted toward the low-pressure flow in the nidus when there is an unbalance in between low- and high-pressure systems.
The lymphatic system can help the venous system with the regulation of resistances, but in complex AVMs this is usually not enough. As a systemic compensatory response and to maintain peripheral resistances, there is an increased heart preload resulting in an increment of venous pressures. Eventually, this results in chronic venous insufficiency and severe venous hypertension ${ }^{1}$. These decompensated phase leads to tissue ischemia and retrograde blood flow with symptoms such as swelling, pain, ulcers, venous dilation, and bleeding ${ }^{4}$.

The treatment of AVMs should always be multidisciplinary. Initially, the approach is always conservative with compression and medical treatment but when an invasive management is indicated, endovascular techniques and surgical resection are the options. A hybrid treatment with endovascular embolization and then surgical resection is the goal, in cases where surgical resection is not possible due to inaccessible location, endovascular treatment and sclerotherapy are the initial choices ${ }^{10}$. Multisession endovascular therapy is preferred to decrease the risk of potential complications.

The patient had a surgical background, symptoms such as pain, varicose veins, swelling, and a chronic internal malleolus ulcer; he also had dilated right ventricle and biauricular dilation in the echocardiogram. For this patient, the presence of symptoms and the systemic involvement were indications for an invasive treatment. The AVM had a deep location and multiple arteriovenous fistulas which make it unreachable for pure excisional surgery, together with the high bleeding 


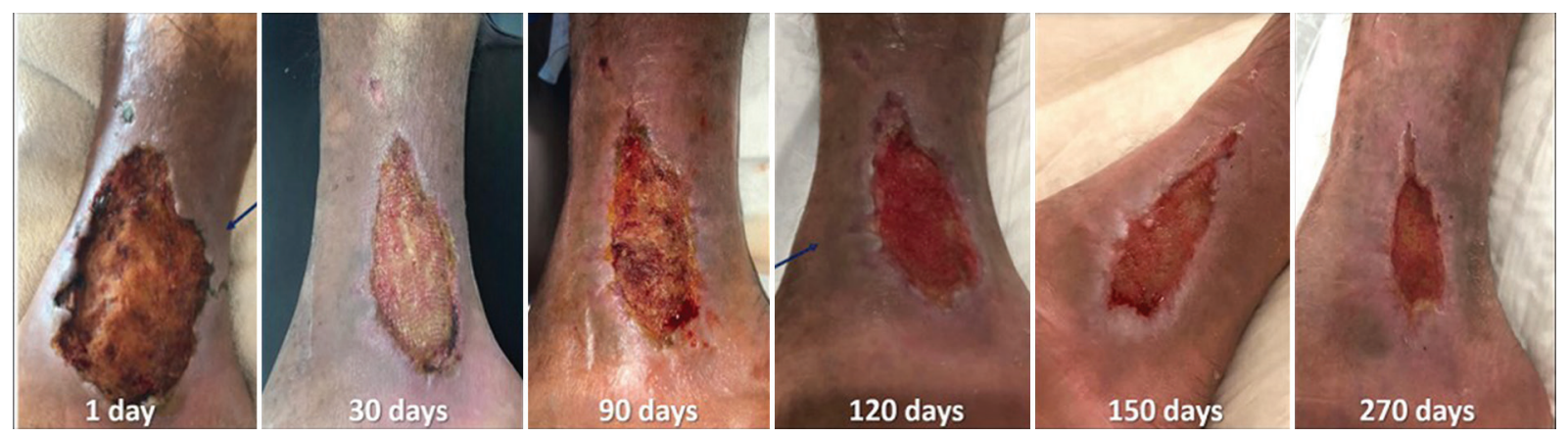

Figure 5. Evolution of the ulcer in the medial malleolus that in day 1 measured $7 \times 8 \mathrm{~cm}$ with irregular and necrotic borders. After multisession endovascular treatment, with significant improvement in size and depth.

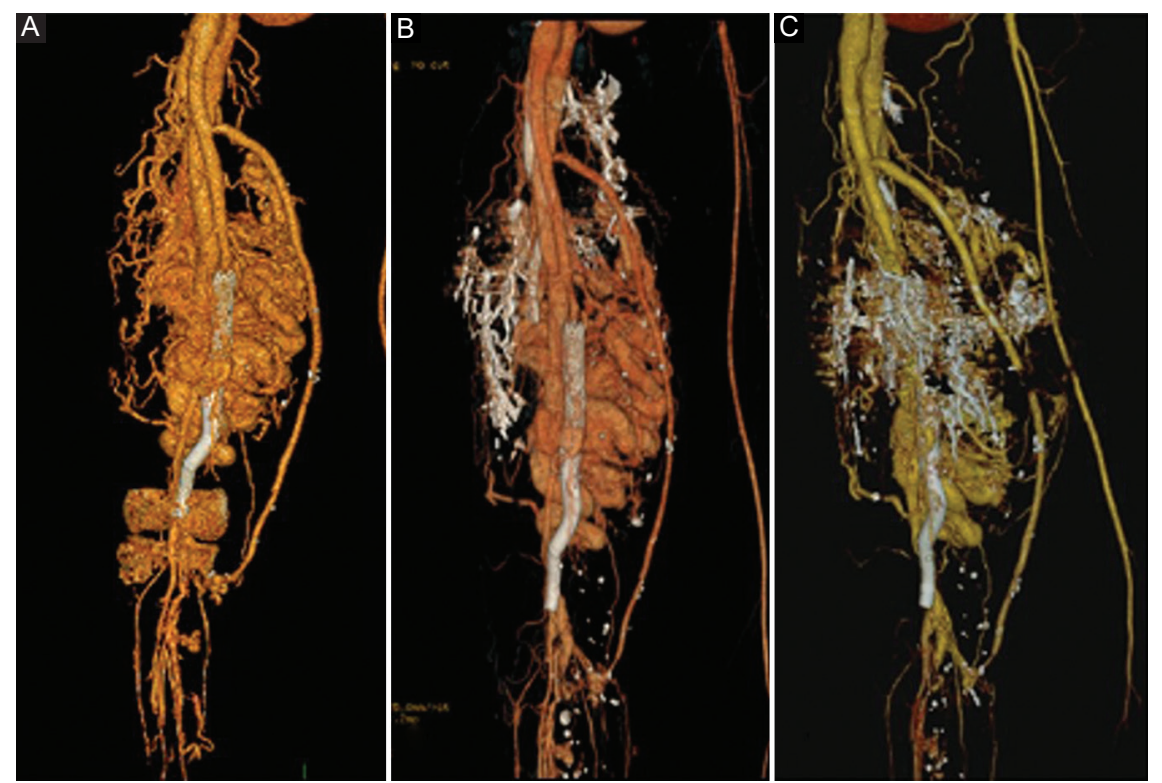

Figure 6. Preoperative and control CTA 3D-reconstructions that showed the significant improvement after treatment. A: preoperative. B: 3 months after treatment. C: 9 months after treatment.

complications that could be encountered if that approach was initially chosen. When a complete open surgical resection is not performed there is a high risk of recurrence but in many cases, this cannot be done so endovascular procedures are an excellent option to decrease the risk of bleeding and improve patient's symptoms and quality of life. To select the best embolic agent for each patient, one must determine the anatomical location and the desired level of occlusion of feeding arteries. Onyx-34 (8\%) administered through microcatheters and controlled liberation coils are good options for embolization in these cases and decrease the risk of migration and ischemic complications. The presence of the surgical background (bypass and previous stents) increased the risk of ischemic complications of the limb that is why a cautious multi-session endovascular embolization was performed.

We decided to follow-up on the venous aneurysm with CTAs and US. High-flow to the venous aneurysm is now significantly diminished and the aneurysm has not grown in 1 year so it has been decided to perform no intervention unless there are clinical changes during follow-up.

\section{Conclusion}

Endovascular approach is an effective and safe option for the management of complex high-flow AVMs. Embolization should be done carefully to prevent complications which could threaten the patient's limb or even life. 
An accurate initial diagnosis is the key for the election of a successful treatment. To get the best outcome, the treatment should always be multidisciplinary.

\section{Conflict of interests}

The authors declared no potential conflicts of interest with respect to the research, authorship, and publication of this article.

\section{Ethical disclosures}

Protection of human and animal subjects. The authors declare that the procedures followed were in accordance with the regulations of the relevant clinical research ethics committee and with those of the Code of Ethics of the World Medical Association (Declaration of Helsinki).

Confidentiality of data. The authors declare that they have followed the protocols of their work center on the publication of patient data.

Right to privacy and informed consent. The authors have obtained the written informed consent of the patients or subjects mentioned in the article. The corresponding author is in possession of this document.

\section{References}

1. Sicard GA. Rutherford's Vascular Surgery and Endovascular Therapy. New York: Elsevier; 2018.

2. Madani H, Farrant J, Chhaya N, Anwar I, Marmery H, Platts A, et al. Peripheral limb vascular malformations: an update of appropriate imaging and treatment options of a challenging condition. $\mathrm{Br} \mathrm{J}$ Radiol. 2015;88:20140406.

3. Mattassi R, Loose DA, Vaghi M. Hemangiomas and Vascular Malformations: an Atlas of Diagnosis and Treatment. Milan: Springer-Verlag Mailand; 2009.

4. Lee BB, Baumgartner I, Berlien HP, Bianchini G, Burrows P, Do YS, et al. Consensus document of the international union of angiology (IUA)2013 current concepts on the management of arterio-venous malformations. Int Angiol. 2013;32:9-36

5. Larsen AK, Damsgaard TE, Hedelund L. Classification of vascular anomalies. Ugeskr Laeger. 2018;180:11170857.

6. Hyodoh H, Hire M, Akiba H, Tamakawa M, Hyodoh K, Hareyama M. Peripheral vascular malformations: imaging, treatment approaches, and therapeutic issues. Radiographics. 2005;25:159-71.

7. Vaidya S, Cooke D, Kogut M, Stratil PG, Bittles MA, Sidhu MS. Imaging and percutaneous treatment of vascular anomalies. Semin Intervent Radiol. 2008;25:216-33.

8. Lee BB, Baumgartner I, Berlien HP, Bianchini G, Burrows P, Do YS, et al. Current concepts of the management of arterio-venous malformations. Int Angiol. 2013;32:9-36.

9. Ramírez-Senent B, Abadal JM, Vázquez E, Lago I, Gálvez E, Araujo MA et al. Endovascular management of a giant high-flow lower limb arteriovenous malformation. Vasc Endovascular Surg. 2017;51:572-6.

10. Gloviczki P, Duncan A, Kalra M, Oderich G, Ricotta J, Bower T, et al. Vascular malformations: an update. Perspect Vasc Surg Endovasc Ther. 2009;21:133-48.

11. Lee BB, Lardeo J, Neville R. Arterio-venous malformation: how much do we know? Phlebology. 2009;24:193-200.

12. Conway AM, Qato K, Drury J, Rosen RJ. Embolization techniques for high-flow arteriovenous malformations with a dominant outflow vein. J Vasc Surg Venous Lymphatic Disord. 2015;3:178-83.

13. Lee BB, Do YS, Yakes W, Kim DI, Mattassi R, Hyon WS. Management of arteriovenous malformations: a multidisciplinary approach. J Vasc Surg. 2004;39:590-600. 